\title{
Practices and Challenges of Cooperative Learning in Selected College of Arsi University: As a Motivational Factor on Enhancing Students' Learning
}

\author{
Birhanu Moges \\ Department of Psychology, College of Education and Behavioral Sciences, Arsi University, Ethiopia
}

Copyright $\mathrm{O} 2019$ by authors, all rights reserved. Authors agree that this article remains permanently open access under the terms of the Creative Commons Attribution License 4.0 International License

\begin{abstract}
The objective of this study was to examine the practices and challenges of cooperative learning as a motivational factor on enhancing students' learning in selected colleges of Arsi University. This research has mixed approach both qualitative and quantitative; while its method is descriptive and explorative in their nature. The total sample of the study was 421,330 graduate students, 85 instructors and the 8 deans and vice deans were included as a sample through stratified random sampling technique. Instruments employed in this study included questionnaire, semi-structured interview and observation. For questionnaire a five point Likert scale was adopted. Frequencies, percentage, mean and SD was used to analyze the data. Information generated from interview and classroom observation was described qualitatively. The findings indicate that instructors and students have positive attitudes towards cooperative learning and they prefer it to lecture-style. The findings suggest that training in cooperative learning is important to implement it. Accordingly the following findings were obtained: instructors' lack of knowledge and training on cooperative learning; students' lack of interest to participate in cooperative learning and passive style of learning; lack of enough support from administrative and unavailability of instructional materials were among the challenges which hinder the implementation of cooperative learning. Consequently, instructors are practicing traditional teaching methods. Similarly, students indicated that they are not willing to participate in group discussion while the researcher observed in the actual classroom. The challenge for instructors is to develop skills to facilitate positive teamwork experience among their students who will need to interact with each others in transnational teams in the workplace of the future. It can be recommend, providing adequate administrative support, preparing supplementary materials, preparing cooperative learning training for instructors and inviting experts to share experience about cooperative learning. Cooperative learning method should be adopted by all instructors as an effective learning
\end{abstract}

strategy in order to improve students' learning.

Keywords Challenges, Cooperative Learning, Higher Education, Practices, Student-Centered

\section{Introduction}

\subsection{Background of the Study}

Teaching methods vary with the extent to which they involve the learners or with the roles the students and instructors assume during the teaching-learning process. At one end, there is a teacher dominated method which involves the most direct way of transmitting knowledge to the learners. Here learners are considered as passive listeners. What is expected from students is to absorb simply what is said by the teacher and this is often labeled as the teacher-centered method. According to ICDR as cited in [21], in this method the teacher use "chalk and talk" or method of teaching in which the instructor is active and the students passively copy the notes in their exercise book or memorize the information from their text books. The traditional methods of teaching unfortunately have failed to ensure the quality learner. According to [1], the existing classroom environment does not support the implementation of interactive teaching methods. Traditional methods in teaching-learning were teacher-centered and often created classroom atmospheres in which learners competed with each other. The traditional model is foster competition rather than cooperative learning (CL) method which is favored by the major students. Educators also believe that minority students might fall behind higher achieving students in this kind of learning environment, i.e., traditional models of competitive learning. According to [24], traditional instructions, such as lectures, explanations, 
answer-question routines, assigning reading, and guided practice focus exclusively on individual academic goals.

While, effective teaching is based on several factors such as positive reinforcement, advance organizer, cues and feedback, higher order questioning, positive classroom environment and cooperative learning [30]. It is therefore imperative for an instructor to be well equipped with all these teaching tools proceeding towards their classroom in order to produce better results. To this end many methods and strategies have been identified and practiced that has produced better and encouraged results. Among these the cooperative learning (CL) is most widely used and preferred method of teaching [47]. CL is one of the most commonly used forms of active teaching-learning process. Taking place through an individual's interaction with his or her environment and peers, cooperative learning is largely based on the idea that students learn through social contexts [19]. The term CL refers to students working in teams on an assignment or project under conditions in which certain criteria are satisfied, including that the team members be held individually accountable for the complete content of the assignment or project $[4,25]$. According to [3] " $\mathrm{CL}$ is an organizational structure in which a group of students pursue academic goals through collaborative efforts. Students work together in small groups, draw on each other's strengths, and assist each other in completing a task." As [26] said "CL is the instructional use of small teams so that learner's work together to take advantage of their own and each other's learning." In CL, members are placed in groups of two to six individuals to work on a definite assignment. CL tasks vary widely, ranging from understanding and explaining a new concept to solving a new problem, analyzing a situation, or confronting a dilemma. In a typical task, students might share individual knowledge with their group or have specific roles to play, and the group would be jointly responsible for arriving at an agreed-upon solution.

While CL has been found to be an effective pedagogical tool in a broad range of subjects, limited research explores this form of active pedagogy as it pertains to higher education, and specifically the communication field. CL has increasingly become a popular form of active pedagogy employed in academic institutions. CL is a new approach which is supported by research because of its motivational effects on the learner and learning. Over the last three decades, CL method has been widely researched and a number of studies indicate the effectiveness of using this method to improve learners' social and academic performance when working in small groups $[1,20]$. However, many instructors and learners still have difficulties and doubts about implementing CL productively $[9,10,5,46]$.

There are several reasons why CL works as well as it does. The idea that students learn more by doing something active than by simply watching and listening has long been known to both cognitive psychologists and effective teachers [24] and CL is by its nature an active method.
Beyond that, cooperation enhances learning in several ways. Weak students working individually are likely to give up when they get stuck; working cooperatively, they keep going. Strong students faced with the task of explaining and clarifying material to weaker students often find gaps in their own understanding and fill them in. Students working alone may tend to delay completing assignments or skip them altogether, but when they know that others are counting on them, they are motivated to do the work in a timely manner.

Further, CL method, often recognized as learner-centered, have emerged in opposition to the more traditional methods in which the instructor plays a major role in class. CL is a successful teaching method in which small groups, each with students of various levels of ability, use a multiple of learning activities to improve their understanding of a subject. Each member of a team is answerable not only for knowledge what is taught but also for helping other team members to learn, thus developing an environment of success. CL is a learner-centered approach of teaching and is said, when effectively used by instructors, to create an affective learning classroom. In general, research results are in favor of CL [18]. Students work from beginning to end the assignment until all group members successfully comprehend and complete it. They work in group to gain from each others efforts; they share a common fate, work in cooperation and feel proud for group success. CL is a teaching method that helps students learn together in groups to maximize their learning with great interest and motivation $[8,32,34,43]$.

CL has group goals that create what is known as positive interdependence. Positive interdependence is when students believe they can reach their learning goals only when other students in their cooperative group also reach their goals [10]. Positive interdependence means that individual accountability must occur. Cooperative groups work together to earn rewards, grades and recognition. There is consensus among CL reviewers that individual accountability and positive interdependence are actually essential components for successful CL [13]. CL is a teaching method, in which students of diverse background are assembled in groups to accomplish a common task [37]. It helps students to build rapport with other students [39]. $\mathrm{CL}$ tasks promote interaction and cooperation among group members that leads to gain more academic and social competencies than working as an individual [35,41]. [37] that $\mathrm{CL}$ promotes students ' learning motivation and critical thinking. According to [8] Cooperative learning facilitates to develop better relationship among gifted, average and below average learners, enhance their self-esteem and improve their attitude towards teaching subject. $\mathrm{CL}$ is an extensive research based strategy [31,37].

Research findings show that CL method sponsor student learning and educational attainment; amplify student maintenance; improve student satisfaction with their learning experience; help students develop skills in verbal statement; increase students' social skills; enhance student 
self-esteem; help to promote positive race relations [19, 22]. Further, Findings of various researches support the benefits of CL in the area of academic success and social skills [40]. These findings motivate teachers to use $\mathrm{CL}$ in their classrooms. Similar findings were also reported in another study by [441] indicating that CL showed a significant effect on students' academic achievement. CL is not only the group work. A basic difference between cooperative learning and traditional group work is that in classical group work, students are asked to work in groups with no attention compensated to group functioning, whereas in CL, group work is carefully organized, planned, and examine [32]. Instructional models and structures have been designed, which teachers can adopt and adapt, to help the group work operate more successfully by creating an atmosphere for interactive learning [31].

[16] Found no evidence that the CL approach had any advantages over more traditional teaching methods. He aimed to investigate the influence of $\mathrm{CL}$ in comparison with lecture-style on students' attainment in grade 11 curriculum. The key data collection tool was also pre- and post-test with control and experimental groups. The results indicated that the students' attainment in the control group (lecture-centered) was considerably better than the students' attainment in the experimental group-the one using CL. Mutual understanding among team members decreased task conflicts among them. [20]interviewed seven teachers who were implementing CL for more than two years found that the teachers were holding positive perceptions about CL indicating that it helped students in gaining confidence, improving academic achievement and preparation for future job market.

Finally, there are several reasons why cooperative learning works as well as it does. The idea that students learn more by doing something active than by simply watching and listening has long been known to both cognitive psychologists and effective teachers $[26,31]$ and $\mathrm{CL}$ is by its nature an active method. Beyond that, cooperation enhances learning in several ways. Weak students working individually are likely to give up when they get stuck; working cooperatively, they keep going. Strong students faced with the task of explaining and clarifying material to weaker students often find gaps in their own understanding and fill them in. Students working alone may tend to delay completing assignments or skip them altogether, but when they know that others are counting on them, they are motivated to do the work in a timely manner.

\subsection{Statement of the Problem}

Prior research on active learning approach has supported the effectiveness of $\mathrm{CL}$ on test achievement for example, Felder and Brent cited in [12, 20, 21, 442]. Findings on team-based learning suggest that this pedagogical method is successful in promoting both problem-solving and critical-thinking skills. Students who perceive grades as important in a class are also expected to perform better academically than those who attribute less importance to grades. Further, an essential element of CL is one's contribution to help achieve the group's goal [19]. This form of active pedagogy is centered on the notion of teamwork and group orientation, interdependence, and success. Those who view accomplishment and the attainment of satisfaction through the group are predicted to be greater participants in the cooperative learning process.

However, study by [19] identified several factors standing against the successful implementation of CL. One of such factors identified was a teacher-related problem, which is the instructional strategy adopted by teachers in colleges. The teachers' inability to use appropriate CL methods in the classrooms negatively affects students' ability to acquire the necessary attitudes, knowledge and skills required to produce a workforce for development of the Ethiopian nation. Application of CL to education is a universal practice as [24]noted that CL is now utilized in schools and universities throughout most of the world in every subject area and from preschool through graduate class. CL changed the theory of traditional methods of teaching. The traditional methods of teaching have insufficient to teach so there is need to integrate it with CL which is students centered approach use to change teaching learning environment for betterment of learners and their academic achievements.

According to [40], in the case of Ethiopia in 1994 a New Educational Training Policy was designed which introduced a lot of changes in the implementation of educational activities. Realizing the importance of effective teaching-learning approach in empowering the quality of Ethiopian human learning, the government of Ethiopian has decided active learning approach like CL to be one of the compulsory strategies for educational levels. To enable students to improve their learning ability, it is necessary to implement the CL method of teaching which encourage students to communicate as effectively as possible. The majority of studies indicated that positive results in relation to achievement when using $\mathrm{CL}$ in comparison with traditional methods, some of these studies still argue that there is a need for further research on the practice and challenges of cooperative learning approach in different stages and curricula [23, 28, 48].

Even though, some researchers have done studies that related with the idea of cooperative learning. Like [16] has studied on the role of cooperative learning in enhancing students' writing performance. In a similar way, [39,48] have studied on the practices of cooperative learning, effects of cooperative learning on reading comprehension achievement in EFL and social skill, and perception and classroom practice of CL in EFL classes in secondary and preparatory schools respectively. Some of the challenges are connected with the potential difficulty in carrying out CL in large classes, improper classroom organization, lack of necessary teaching materials, well trained instructors [34]. Further, [11, 33, 45] found out that, lack of students 
accountability for their learning, lack of motivation, lack of awareness, teachers attitude, shortage of instructional materials, lack of clear guideline, teachers recklessness, reliance of lower achievers on higher achievers, lack of training on how to implement $\mathrm{CL}$ and students reservation to get actively involved in $\mathrm{CL}$ were the main challenges that hampered the implementation of CL. According to [7, 33], instructors are still playing dominant roles to guide and control the learning process. The activity based on CL helps instructors to facilitate learning and to recognize how the teaching-learning process is going on. In instructors' role as a facilitator, they must move around the class helping students and groups as needs arise. A class activity which does not give students a chance to interact and practice exercise may be said that it lacks CL.

This study has been chosen for a number of reasons. Firstly, there are educational aspects since it could be helpful to know whether CL can have an impact on what instructors who are familiar with traditional teaching methods plan and do in their lessons when attempting to use it. Secondly, in academic terms, studies on the use of $\mathrm{CL}$ in Ethiopian higher education are considered to be still in their infancy $[7,11,12]$. To the best knowledge of the researcher, this could be the first study in the higher education to investigate the practices and challenges on implementing CL in Arsi University. Furthermore, the results of the present study can possibly inform practices in other higher education institute in Ethiopia since all universities in the country follow the same system and processes in terms of the assessment and curriculum [14, $16,21,33]$.

Finally, the researcher was motivated to investigate practices and challenges of cooperative learning in selected colleges of Arsi University as a motivational factor on enhancing students' learning as well as instructors and students perceptions, as the basis upon which this investigation is conducted because of two main reasons. First, the researcher observed that cooperative learning method is not practiced as expected in the university level. Second, as a knowledge of researcher from different literature, relative to students taught traditionally, that is with instructor-centered lectures, individual assignments, and competitive grading were highly practiced; while CL has advantages in cooperatively taught students tend to exhibit higher academic achievement, greater persistence through graduation, better high-level reasoning and critical thinking skills, deeper understanding of learned material, greater time on task and less disruptive behavior in class, lower levels of anxiety and stress, greater intrinsic motivation to learn and achieve, greater ability to view situations from others' perspectives, more positive and supportive relationships with peers, more positive attitudes toward course areas, and higher self-esteem.

\subsection{Objectives of the Study}

The general objective of this study is to investigate the practices and challenges of cooperative learning as a motivational factor to enhance students' learning in selected colleges of Arsi University. The specific objectives of the study are:

- To assess instructors' and students' Opinion towards cooperative learning practices and challenges in selected college of Arsi University

- To identify the main challenges in implementing cooperative learning method in selected colleges of Arsi University.

- To examine the university environment conduciveness for the implementation of cooperative learning method took place in a traditional lecture-style teaching and learning context.

\subsection{Research Questions}

To achieve the objective of this study, the researcher was attempted to answer the following research questions.

1. What are instructors' and students' Opinion toward cooperative learning practices and challenges in selected College of Arsi University?

2. What are the main challenges in implementing cooperative learning method?

3. How the college environment is conducive to implement cooperative learning method?

\subsection{Significance of the Study}

The researcher hopes that the findings of this the study would have the following contributions for the instructors, students, department heads, deans, higher education institutes and researchers. This study might help instructors to develop their understanding about $\mathrm{CL}$ and it might help them to provide methodological insights and information about CL which are helpful for them and students to effective implementation of CL. Show the challenges of implementation of $\mathrm{CL}$ and solution to overcome those changes. It also hoped to give some insights for professionals that develop curriculum and teaching materials in order to help students including activities that entertain the use of CL. The instructors who have not used $\mathrm{CL}$ in their classes may be encouraged to use it after seeing that carefully designed CL activities may be used in the instruction. If there is a positive response to $\mathrm{CL}$ the teachers who see an influence of CL on learners' attitudes to courses may want to design their own cooperative learning activities.

The findings of this study may help higher education institutes-universities in making future decisions on whether instructors at the university need to be trained to implement this CL method as part of their practices and challenges of CL in selected colleges of Arsi University as a motivational factor to enhance students' learning. Because there is a lack of research in the field of practices and challenges of CL and the effects of its on students' and 
instructors' perception, the results of this study may contribute to the literature in these areas. In addition, the results may provide information to compare teacher-centered and student-centered approaches of teaching-learning at university level.

\subsection{Delimitation of the Study}

The need to investigate practices and challenges of the implementation of CL may require wider coverage of sample in different educational institutes and at various levels. Primarily, it is worth keeping in mind that the sample size of the study was limited to only one university 85 instructors, eight college deans and their vice deans and 330 graduate students as a totally of 423 participants were included in this study. This could often create danger to made generalization to all universities in the country.

\section{Research Design and Methodology}

\subsection{Research Design}

Mixed-method research design more focused on explanatory design can help the researcher to benefit from the strengths and minimise the weakness of both quantitative and qualitative approach of data collection and analysis in one study $[14,15]$. Explanatory design is that qualitative data helps explain or build upon initial quantitative results [15]. According to [15], this design can also be used when a researcher wants to form groups based on quantitative results and follow up with the groups through subsequent qualitative research or to use quantitative participant characteristics to guide purposeful sampling for a qualitative phase. In the present study, gathering the data from quite a large number of instructors and students regarding their practices, challenges and perceptions of CL was achieved by using questionnaires. The problems of using only quantitative approach can be minimised by using multiple sources of qualitative data, such as semi-structured interviews and observation. The nature of the research questions should inform the research approach to be chosen. Because the research questions in the present study are descriptive and explorative in their nature, they required the adoption of a research approach that could provide both descriptive data of the phenomenon investigated, such as the classroom observations and the demographic data collected through the questionnaire, along with more exploratory analysis of the qualitative data collected through the interviews and observation. Eventually, describe the practices and major challenges block the implementation of cooperative learning method. Therefore, it's rational to say this research is a typical descriptive and explorative of its type and the researcher believe that these method were appropriate to answer the research questions.

\subsection{The Study Area, Participants and Sampling Technique}

Arsi University was selected as a study site for the following reasons. First, the researcher identified the problems in practicing CL method in this university. Second, the researcher is familiar with the instructors, students and deans of the study and its immediacy and easily access to the needed information.

This study was conducted in College of Business and Economics, Education and Behavioral Sciences, Health; and Agriculture of Arsi University. The target population of this study includes college academic staffs (instructors) and regular graduate students. Regarding sample, 85 instructors and the 4 deans and 4 vice dean academic staff members was selected by using simple random and stratified sampling techniques since they have better insight about the cooperative learning practices in the college as well as manageable in size. There are about 1050 graduate regular student populations in 2017/18 academic year in the college. Out of them about $330(31 \%)$ students were selected using quota sampling techniques since number of students in each department is not equal.

In this study the sample comprised instructors and graduate students of Arsi University. By using simple random and stratified sampling techniques both the instructors and students were selected. The rationale behind this is, the instructors were considered to be rich source of data and on the other hand, the overall activities of the colleges are the responsibility of the colleges deans and their vice deans. Students were taken as other sources of data to get important information pertaining to the practices and challenges of CL.

The data summarized in Table 1 indicates that $14(16.5 \%)$ of the respondents were female, whereas, $71(83.5 \%)$ of them were male instructors. As regarding students, $104(31.5 \%)$ of the respondents were female, whereas, $226(68.5 \%)$ of them were male. In order to avoid gender bias every necessary effort has been made to engage both genders equally. But because of number of male students are greater than female in each class, male participants were larger than female (Table1).

Table 1. Sex of Respondents ( $N=85$ instructors and $330=$ students $)$

\begin{tabular}{|l|l|l|l|}
\hline Respondents & Sex & $\mathrm{N}$ & $\%$ \\
\hline \multirow{3}{*}{ Instructors } & Male & 71 & 83.5 \\
\cline { 2 - 4 } & Female & 14 & 16.5 \\
\hline \multirow{2}{*}{ Students } & Male & 226 & 68.5 \\
\cline { 2 - 4 } & Female & 104 & 31.5 \\
\hline
\end{tabular}

\subsection{Methods of Data Collection}

In order to provide a more comprehensive picture of the issue under investigation, data from instructors and students was collected by using a questionnaire, semi structured interviews and classroom observations. 
Semi-structured interviews were used with seven instructors. The instructors were interviewed twice, before and after the classroom observations. The classroom observation checklist also served as a means of collecting data. With regard to the questionnaire, the researcher adapted close-ended questions in order to reduce instructors and students' confusion while filling out the questionnaire. Questionnaire was adapted from $[11,48]$ and prepared for both instructors and students, because the technique was not tiresome and helped the researcher to assess respondents' perception and factors that affect the practices of CL. In addition, because respondents have enough time to read and give well thought out responses in written form without the intervention of the interviewer, it is suitable in the case of big enquires and it is economical in terms of time and energy[14].

In conducting the research, the questionnaire was translated into local language-Amharic for making it easily understandable by students. Although the questions were initially written in English, they were translated into language-Amharic, for the participants. The Amharic versions of the questions were given to two native speakers of Amharic, who are also English instructors, to translate back into English. After this process, necessary adjustments on the questions were made. In answering all these questions, respondents were asked to mark a five-point Likert scale to indicate their level of agreement with each statement. After the researcher's serious correction based on pilot study on the items, the researcher reshaped the instrument and the direction for the items. After preparation, to develop appropriate instrument for the study and to correct unclear and misleading questions, the researcher administered a pilot study at the humanity and Social Science College to 10 instructors' and 15 students, but these respondents were not included in the main study. Then, the internal consistency of the questionnaire was checked using the statistical package for social sciences (SPSS-Version 20.00) and the calculated Cronbach alpha revealed an acceptable reliability (.74).

\subsection{Method of Data Analysis}

The data gathered through questionnaire, interview and observation were analyzed both quantitatively and qualitatively. Accordingly, frequency, percentage, SD and mean scores are used to analyze the quantitative data. In similar fashion, information generated from interview and classroom observation was described qualitatively. The data analysis procedure consisted of likert-type item analysis for all specific objectives of the study. According to Taylor as cited in [15], likert assigned numerical values to responses and the numerical representation of the items went through 'strongly agree' $=5$; $\quad$ 'agree $=4$; 'undecided' $=3$; 'disagree' $=2$; and 'strongly disagree' $=1$. To analyze the response of the questionnaire the raw data entered in to computer to be analyzed using SPSS version 20. The tables were presented before the analysis and interpretation. Finally, based on the mean value each item was presented. Thus, the higher mean value are meant to indicate greater perception, challenges and practice and lower mean value indicate lower perception, challenges and practice towards the item.

\section{Results and Discussion}

\subsection{Respondents' Perception of the Advantage, Practice and Challenges of $C L$}

\subsubsection{Instructors' and Students' Perceptions of CL Practices}

Instructors' and students' CL knowledge affected the way they perceived and managed factors such as students' age and class size, student behaviour, and teacher control and planning. Attempts were made to measure the respondents' responses towards CL.

In general, instructors and students seemed to like CL, with more than half of the respondents being quite positive (agree) about it $(68.2 \% ; 60.6 \%$ instructors and students respectively), but it is also observed that $(18.8 \% ; 15.2 \%$ instructors and students respectively) were very positive about it (strongly agree). When asked whether they preferred to be taught by $\mathrm{CL}$ or traditional methods, the majority of instructors and students indicated that they preferred CL by either agreeing ( $49.4 \%$ instructors; $42.4 \%$ students) or strongly agreeing (30.3\% students; $15.3 \%$ instructors) with the statement. The majority of respondents either agreed or strongly agreed with the statement on the possibility of learning any subject with CL. When asked whether the possibility to learn /teach any course with CL method, about it $(87.1 \%$ instructor and $78.8 \%$ student) respondents both strongly agree either agrees. Similarly, majority of instructor $72.9 \%$ and student respondents $57.6 \%$ ) strongly agree either agree the course that is taught by using CL (Table 2, below). This corroborates the findings of a number of previous studies $[18,27,29]$. All instructors and most students seemed to agree that CL lessons contributed to the enjoyment of learning since students could actively carry out some research build up their own knowledge and engage in discussions instead of passively listening to the teacher. In the interview explained that:

It depends on the topic and the subject studied. Some topics or some contents are not compatible with the CL. The traditional method is effective in presenting complex information that we cannot learn on our own. For example, in the medicine class, students are usually acquainted with many of the topics so CL is more effective than the traditional method. However, in accounting, some axioms and laws are new to students and difficult to understand without the instructor's help. Only after the instructor's explanation can students work using $C L$. 
Table 2. Instructors' and Students' Opinion towards CL practices

\begin{tabular}{|cc|l|c|c|c|c|c|}
\hline \multicolumn{1}{|c|}{ Items } & Respondents & SA & Agree & Not sure & Disagree & SDA \\
\hline \multirow{2}{*}{1.} & I like CL in the classroom & Instructors & $16(18.8 \%)$ & $58(68.2 \%)$ & $4(4.7 \%)$ & $2(6.1 \%)$ & $2(2.3 \%)$ \\
\cline { 3 - 8 } & Students & $50(15.2 \%)$ & $200(60.6 \%)$ & $40(12.1 \%)$ & $20(6.1 \%)$ & $20(6.1 \%)$ \\
\hline \multirow{2}{*}{2.} & $\begin{array}{l}\text { I prefer to be taught by CL compared to } \\
\text { traditional methods }\end{array}$ & Instructors & $13(15.3 \%)$ & $42(49.4 \%)$ & $12(14.1 \%)$ & $10(11.8 \%)$ & $10(11.8 \%)$ \\
\cline { 3 - 8 } & Students & $100(30.3 \%)$ & $140(42.4 \%)$ & $50(15.2 \%)$ & $20(6.1 \%)$ & $20(6.1 \%)$ \\
\hline \multirow{2}{*}{3.} & $\begin{array}{l}\text { I think it is possible to learn /teach any } \\
\text { course with CL }\end{array}$ & Instructors & $18(21.2 \%)$ & $56(65.9 \%)$ & $6(7.1 \%)$ & $2(6.1 \%)$ & $3(3.5 \%)$ \\
\cline { 3 - 8 } & Students & $110(33.3 \%)$ & $150(45.5 \%)$ & $30(9.1 \%)$ & $10(3.0 \%)$ & $30(9.1 \%)$ \\
\hline \multirow{2}{*}{4.} & $\begin{array}{l}\text { I like the course that is taught by using } \\
\text { CL }\end{array}$ & Instructors & $28(32.9 \%)$ & $34(40 \%)$ & $10(11.8 \%)$ & $5(5.9 \%)$ & $8(9.4 \%)$ \\
\cline { 2 - 7 } & Students & $70(21.2 \%)$ & $120(36.4 \%)$ & $100(30.3 \%)$ & $10(3.0 \%)$ & $30(9.1 \%)$ \\
\hline
\end{tabular}

The data present in Table 2, indicates that the majority of instructor and student respondents had positive views of $\mathrm{CL}$ and either agreed or strongly agreed with the affirmative statements presented. This suggests that the respondents' perception towards $\mathrm{CL}$ is closer to the rating point 'agree' i.e. score of responses of 4 . This tells us, the respondents' perception towards CL is good (Table2). The statistical findings are corroborated by data from the interviews. Some students and instructors provided reasons behind their preference for the CL lessons. All the instructors indicated that students could academically and socially benefit from using CL. One of the most important academic benefits mentioned was motivation. All the instructors mentioned that $\mathrm{CL}$ enhances students' motivation to learn. Other explained that, "students in the group encourage each other to work together in order to achieve mutual goals. These shared goals motivate students to work and learn." Similarly, Instructor respondent said, "When students have opportunity and bear the responsibility, productivity is increased. At the same time, they receive support from their teammates and the teacher to achieve the shared goal".

For example, one of student respondent said that, "I actively and cooperatively work with my group members in order to understand a specific piece of information. This is very enjoyable to me. Now, I have role in the class to play. I search about the information, understand it and discuss it with my teammates. However, in the lecturing method, I feel bored and just passively listen to the teacher". Similarly, instructor respondent also commented on the enjoyment and active participation and added that "It is more enjoyable than the lecturing method when I teach to the students' talk and there is no other voice". Furthermore, second student said he preferred to be taught by cooperative learning because he benefited from it more than from traditional teaching methods. Further, He mentioned that, "this atmosphere helps to create new friendships and makes CL quite fun and usually I get good grades-better than I get by using the lecturing method. In the lecturing method, the instructor does not allow conversation between students, and he punishes those who do so. Also, I get bored and feel sleepy listening to the instructor's explanation for may be more than 45 minutes".
One of the most important advantages pointed out by all the respondents is the enjoyment they take from teaching using CL. One of the instructor respondent observed that, "learning became more enjoyable and fun" in contrast with the lecture-style that he believed was responsible for the "boring" atmosphere in class. Other also mentioned the fun aspect of CL and stated that, "the source of joy" is possibly because students "actively engage in discussions and this creates a more relaxed atmosphere". Another reason for such enjoyment is provided by respondents, who believe that this is due to the fact that in CL "students are not passive as in traditional teaching methods". One instructor also believes the main reason for an enjoyable atmosphere is that students participate in the lesson instead of having the "teacher talking throughout the entire class". Another argued that CL is a "more pleasing method" because it is "more effective and brings more benefits to students than the lecture-style lesson".

The instructor and student interviews indicate that group composition may be a key factor behind students' preferences. As an example, one student respondent said that she preferred CL when she works "with an interactive and participative group"; however, when group members did not participate and provide help to others or "when all group members are weak students and they cannot complete the group's task" she preferred the "lecturing method and working alone". Personal relationships also seem to play an important role according to one of respondent, who said that "sometimes some group members do not like working with me and I do not like working with them or other students who want to dominate the group's discussion, and I prefer to be taught by the lecturing method than working with these kinds of students".

Attempts were made to find out respondents perception of CL. Regarding this instructor's interview on item 3, asked about the importance of cooperative learning and he replied that "Cooperative learning helps students to increase their participation since they can share ideas and it also helps to increase their self-confidence". It shows that the instructor had good perception about the benefit of CL, but it is not that much detail and it may be because of lack of practicing on cooperative learning. Although an 
extensive body of research confirms the effectiveness of $\mathrm{CL}$ in higher education $[33,39]$, cooperative learning has several limitations. Instructors are often confronted with resistance and hostility from students who believe they are being held back by slower teammates [38]. In addition, such negative reactions come from the other side where weaker and less assertive students complain of being belittled or ignored by more responsive students. The desire to take part in a task and the significance of achievement and grades to students may only be limited factors that affect the degree to which a student is active in a group setting.

Moreover, the instructor was asked whether he participated in seminars or workshops on cooperative learning (Item4). If your answer is yes, how did you find it? $\mathrm{He}$ replied that "yes but that was not specifically on $C L$ rather on active learning that I got the training before two years by the non-governmental organization for three days". And he also said that "the methodology was good and I accepted it". Here, we can conclude that the instructor has positive perception on CL because he answers the questions positively. Finally, the instructor was asked about feelings that he observed from his students when they engage in CL. He replied that: "most of students have preferred a traditional style of learning. They need more explanation from their instructor. But few students show their interest to participate actively in group work. Majority of the students are not interested in participating in group work.

From this we generalize the students' traditional style of learning and their lack of interest are major problems which facing instructor while he/she try to implement CL. In addition to the information obtained through quantitative data analysis, students' interview result indicates that students had a positive perception towards CL because most students replied the questions positively as follows. The students were asked, "Do you like working cooperatively with your classmates? Why?" Most participants responded that they like doing tasks cooperatively with their classmates than doing individually. This were helped the students to share new ideas and concepts. Another question asked whether they feel that they learnt better in groups than working by themselves was forwarded to the interviewee and almost all participants replied 'yes it is, because we don't know everything well and when we are doing in groups we score a good result". Additionally, respondents responded that the lessons were clear when they helped each other. With regard to related item, that was whether working cooperatively increase their participation in class or not and why/ why not? the majority of the study subjects replied that "yes, it increase our participation because during the discussion we got good understanding on the activities and due to this we motivated to participate actively". Question was also raised to participants regarding the benefit of $C L$ in titled, what benefits are there in learning or studying cooperatively with others? All respondents had awareness about the benefit of CL. Among the benefits were that CL foster their participation, share ideas and experiences; help them to be learning more from their peers. In general, we can conclude that majority of the respondents have good perception of CL. Similar findings were reported by[27,30, 33, 37], who argue that CL increased their participants' motivation to learn in comparison to traditional lecture instruction due to the interactive and goal shared nature of the activities performed in class. [5] also found that working in teams where group members feel that their individual contributions are relevant to the group's success resulted in increased motivation to learn. The results support the argument in favour of $\mathrm{CL}$ in comparison to lecture-centered regarding achievement proposed by $[6,28,38]$.

Finally, most instructors mentioned that students' increased academic achievement was another benefit of CL. For example, they commented that, "When using the method of traditional lecturing, only six to eight students out of 30 may get high marks. However, with the CL method, you find only about three to five students whose marks are just within average, but the rest of the students have gained high marks." Similarly, other said, "it is very likely that students' grades get higher since they do understand and digest information more effectively".

In general, instructors' and students' perceptions of CL can be considered fairly positive, with the majority of the instructors and students saying that they liked cooperative learning and preferred to be taught by this method. However, some students were still not sure about that or preferred the lecturing method. The reasons mentioned above, along with the drawbacks of using CL, may be some of the reasons why some students disagreed with the social and academic benefits of using CL.

\subsubsection{The Main Challenges/Factors in Implementation of Cooperative Learning}

In the questionnaire, instructors and students were also asked to consider the possible challenges and problems posed by learning through CL. Instructors indicated that there are four main challenges and difficulties that seem to affect their use of cooperative learning: the existence of large number of students in one class; uncomfortable seating arrangement of students; lack of clear guide line to practice CL; and problem of group organization/arrangement. 
Table 3. The main challenges in implementation cooperative learning

\begin{tabular}{|c|c|c|c|c|}
\hline No. & Items & Response & Mean & SD \\
\hline A & Classroom related factors affecting the ICL & & & \\
\hline \multirow{2}{*}{1} & \multirow{2}{*}{ The existence of large number of students in one class } & Instructors & 4.53 & 0.49 \\
\hline & & Students & 4.51 & 0.78 \\
\hline \multirow{2}{*}{2} & \multirow{2}{*}{ Uncomfortable seating arrangement of students } & Instructors & 4.57 & 0.49 \\
\hline & & Students & 4.55 & 0.67 \\
\hline \multirow{2}{*}{3} & \multirow{2}{*}{ Lack of clear guide line to practice CL } & Instructors & 1.43 & 0.63 \\
\hline & & Students & 1.4 & 0.59 \\
\hline \multirow{2}{*}{4} & \multirow{2}{*}{ Problem of group organization/arrangement } & Instructors & 3.54 & 0.23 \\
\hline & & Students & 3.62 & 0.12 \\
\hline $\mathrm{B}$ & Student related factors affecting the ICL & & & \\
\hline \multirow{2}{*}{5} & \multirow{2}{*}{ Lack of awareness about cooperative learning } & Instructors & 2.93 & 0.80 \\
\hline & & Students & 3.30 & 1.01 \\
\hline \multirow{2}{*}{6} & \multirow{2}{*}{ Lack of interest in cooperative learning } & Instructors & 3.43 & 1.11 \\
\hline & & Students & 2.71 & 0.92 \\
\hline \multirow{2}{*}{7} & \multirow{2}{*}{ Reluctance of students to participate during cooperative learning } & Instructors & 3.64 & 0.98 \\
\hline & & Students & 3.55 & 1.05 \\
\hline \multirow{2}{*}{8} & \multirow{2}{*}{ Unwillingness of students to take responsibilities as they are assigned for their work/responsibility } & Instructors & 3.79 & 0.98 \\
\hline & & Students & 3.60 & 0.92 \\
\hline \multirow{2}{*}{9} & \multirow{2}{*}{ Domination of some students over the others during group work } & Instructors & 3.29 & 1.11 \\
\hline & & Students & 2.65 & 0.97 \\
\hline \multirow{2}{*}{10} & \multirow{2}{*}{ Lack of confidence to express their views } & Instructors & 2.64 & 0.90 \\
\hline & & Students & 2.50 & 1.00 \\
\hline \multirow{2}{*}{11} & \multirow{2}{*}{ Poor educational background of students } & Instructors & 3.07 & 1.11 \\
\hline & & Students & 3.00 & 0.87 \\
\hline \multirow{2}{*}{12} & \multirow{2}{*}{ Unequal sharing of task among group members } & Instructors & 3.93 & 0.91 \\
\hline & & Students & 3.61 & 0.90 \\
\hline
\end{tabular}

As depicted in Table 3 above, the mean score of respondents for item 1 and 2 is above 4.5 . This indicates that, the existence of large number of students in one class and uncomfortable seating arrangement of students were extremely affecting the implementation of CL. In addition to this, lack of clear guide line to practice $\mathrm{CL}$ and problem of group organization/arrangement were highly affecting the implementation $\mathrm{CL}$ as indicated in item 3 and 4 of Table 2. By supporting this, one of the interviewed student explained "the major factors affecting the implementation $\mathrm{CL}$ in our college are large class size and uncomfortable seats to practice CL". Yet, [7] found out that, large class size is serious problem affecting the implementation of active learning. Moreover, [33] added that, shortage of time is serious problem hindering students to practice student centered method of teaching. In different way, shortage of students' text books is almost never affected the implementation CL as its mean score is less than 1.49 in Table 3 above.

Similarly, as indicated in Table 3, the mean score of item $5,6,9,10,11$ and 12 are between 2.5 and 3.49. This indicates, student related factors such as lack of awareness about CL, lack of interest in CL and domination of some students over the others during group work were moderately affecting the implementation of CL. By supporting this, [7,44] affirmed that; students' interest, belief and commitment affected the implementation of CL in universities. [35]also acknowledged that student motivation to work in groups; poor English language ability and dominance of some students during group work were major problems hindering the practice of CL. Item number 7,8 and 12 of Table 3 also showed that, reluctance of students to participate during $\mathrm{CL}$, unwillingness of students to take responsibilities and unequal sharing of task among group members were highly affecting the implementation of $\mathrm{CL}$ as their mean score was between 3.5 and 4.49. In support of this, data obtained through observation check list also indicated that, unequal sharing of task among members of group and domination of few students at the time of doing activities were observed. Moreover, the result of interview held with one of the principals indicated "some students are carless, they do not take their responsibility, and they need to gain benefits being on the shoulder of others." 
As indicated in Table 4 above, the mean score of all items except item number 1,3 and 4 are between 3.5 and 4.49. This indicates instructor related factors such as their inability to share responsibility for each group members, lack of skill to manage activities during CL and inclination of interest towards lecturing method are highly affecting the implementation of CL. In similar manner, majority of observations made by the researcher indicated that instructors faced difficulty in managing $\mathrm{CL}$ and sharing responsibility for each student. Due to this, instructors were observed to rush in to traditional lecturing method in the mean time while practicing $\mathrm{CL}$ and students were observed to become less participant and out of task. Interview conducted with deans and department heads also evidenced that "instructors' lack of attitude on CL and commitment are major factors affecting the implementation of CL". [50] also elucidated that instructors and students' tendency towards traditional lecture method is the major problem that negatively influence the implementation of CL. Table 4 also shows, instructors' inability to provide timely feedbacks and their failure to reorganize group arrangement are highly affecting the implementation CL. In support of this, the result of observation checklist also indicated 7 out of 8 observed instructors were forming groups based on the normal seating style of students without considering their academic ability. However, Andrew stated that, teachers need to vary the composition of groups every week/month/semester so that each student will have a chance to work with a large number of classmates during the term or year. According to [1,17], lack of instructors' commitment was major problems in using CL. Interview results also showed that all the instructors mentioned some problem of group organization/ arrangement that could affect their use of cooperative learning. Two instructors pointed out that classroom composition could be a challenge: "if all or the majority of students in the classroom are low achievement students, their interaction will be very weak and they could not help each other to understand the lesson content" (I3). Another challenge was the existence of large number of students in one class. This was mentioned by seven instructors, with one instructor stating that, "the large number of students in the classroom, sometimes reaching up to 60 students in small classes, obstructs using $C L$ in the class because it is difficult for me and students to move in the class." In addition, four instructors indicated that covering a curriculum that has a heavy load of content and information was another challenge. For instance, one commented that, as "the Ministry of Education requires a certain amount of the content to be taught every course, I sometimes had to return to use lecture-style to quickly cover the curriculum". Similarly, another also said that, "the current syllabus is more perfectly fit to the traditional lecturing method than to this new method as it can accommodate more information and details than cooperative learning". Finally, the assessment strategy was also a challenge that some instructors faced when they used cooperative learning. This was indicated by four instructors.

Table 4. Instructors related challenges/factors in implementation of CL

\begin{tabular}{|c|c|c|c|c|}
\hline No. & Items & Response & Mean & SD \\
\hline \multirow{2}{*}{1} & \multirow{2}{*}{ Lack of awareness about the benefits of cooperative learning } & Instructors & 2.64 & 0.72 \\
\hline & & Students & 3.34 & 0.91 \\
\hline \multirow{2}{*}{2} & \multirow{2}{*}{ Lack of interest (attitude) on cooperative learning } & Instructors & 3.94 & 0.96 \\
\hline & & Students & 3.60 & 0.92 \\
\hline \multirow{2}{*}{3} & \multirow{2}{*}{ Unwillingness of instructors to implement cooperative learning } & Instructors & 2.86 & 0.90 \\
\hline & & Students & 3.88 & 0.98 \\
\hline \multirow{2}{*}{4} & \multirow{2}{*}{ Instructors inability to provide clear procedures on how to perform the activity } & Instructors & 2.93 & 0.80 \\
\hline & & Students & 3.30 & 1.01 \\
\hline \multirow{2}{*}{5} & \multirow{2}{*}{ Inability of instructors to share responsibility for each group members } & Instructors & 4.14 & 0.64 \\
\hline & & Students & 3.98 & 0.82 \\
\hline \multirow{2}{*}{6} & \multirow{2}{*}{ Lack of skill to manage activities during cooperative learning } & Instructors & 4.07 & 0.71 \\
\hline & & Students & 3.65 & 1.02 \\
\hline \multirow{2}{*}{7} & \multirow{2}{*}{ Teachers inability to provide timely feedback/support } & Instructors & 4.29 & 0.71 \\
\hline & & Students & 3.93 & 0.92 \\
\hline \multirow{2}{*}{8} & \multirow{2}{*}{ The inclination of teachers interest towards lecturing method } & Instructors & 3.69 & 1.02 \\
\hline & & Students & 3.55 & 1.05 \\
\hline \multirow{2}{*}{9} & \multirow{2}{*}{ Instructors failure to provide sufficient time in order to deal with the given issue/activity } & Instructors & 3.79 & 0.98 \\
\hline & & Students & 4.21 & 0.98 \\
\hline \multirow{2}{*}{10} & \multirow{2}{*}{ Instructors failure to reorganize group arrangement of students } & Instructors & 3.88 & 0.81 \\
\hline & & Students & 3.98 & 0.73 \\
\hline
\end{tabular}


Secondly, seven instructors mentioned that some students' backgrounds could be a challenge that could affect their use of CL. Two instructors pointed out that the quality of some students could be a challenge. One of them said that students "who tend to be shy and hardly discuss and interact with their peers in the group can impact on the teacher". Another challenge was the students' family background, as indicated by three instructors. One of them explained that, "the use of a cooperative method becomes a real challenge for students who come from a family background that does not promote discussion and dialogue, who are not usually given the opportunity to express themselves." Other also mentioned that some students keep their effort to themselves and do not share their information with others and that, "the families of such students seem to required them be the highest achievers in the classroom and to excel over his peers, discouraging the student from sharing his information with his teammates." In addition, seven instructors indicated that students' long experience with lecture-style was a challenge. For instance, one of them commented that, "this is a big jump for students. This change is not easy and it is considered a challenge to them because of their long term experiences with lecture-style." Finally, students' lack of knowledge and understanding of cooperative learning was another challenge mentioned by four instructors. One of them said that one student approached him saying that the CL method was "not useful". When he enquired about the reason, the student said, "I do not know how to use it". One argued that, "the picture may not be clear to the students, which can affect the teacher's adoption of a cooperative learning method." To support this idea, [36] states lack of effective use of CL by instructors may be due to teachers not having the professional pattern required to use CL successfully. In addition Darry and Terry cited in [21], pointed out that CL seeks the emancipation from the old beliefs that has dominated earlier methods of teaching and thus instructors and students should get the necessary training to challenge their old assumption.

Extra workload on instructors was another challenge. Three instructors mentioned that attending the training programme constituted extra workload. T6 said, "It was something new, and we were requested to do extra work, such as attending the training programme, visiting other teachers in the class, and carrying out certain activities inside the classroom. That weighed much on the teachers in general'. Two instructors mentioned extra workload that was connected to the planning and preparation of cooperative CL itself as a new method. One said, "Instructors need to spend more time and effort to prepare and plan for cooperative learning lessons, especially at the beginning". Moreover, all participants indicated that other instructors who use lecture-style in the same college negatively affected instructors and students who are new to cooperative learning, especially at the beginning. Other instructor commented that, "the comments of instructors who do not use cooperative learning occasionally frustrated me."

Finally, all the instructors mentioned initial challenges that instructors could face when they changed their teaching methods from lecture-style to cooperative learning and that this might lead to instructors being resistant to change. Four instructors indicated that long experience with lecture-style was a challenge at the beginning. One of instructor said that for instructors who "have been using the lecturing method for a long time-some for eight or 10 years- the change to the new method is a real challenge". Another challenge was instructors' conviction of the benefits of the change, as mentioned by five instructors. As an example, one said that, "instructors should feel that the traditional lecturing method is not effective and they have the wish to change to a new one. In addition, the instructors should believe that the new method will benefit them and students more."

The mean score of item number 1, 2 and 4 in Table 5 above is between 2.5 and 3.49. This tells us that, college leaders' inability to follow up the implementation of $\mathrm{CL}$, failure of college leaders to identify instructors that do not implement $\mathrm{CL}$ and their inability to prepare trainings are moderately affecting the implementation of CL. In the same table above, the mean score of respondents was between 3.5 and 4.49 for item number 3 and 5 . This indicates inability of college leaders to provide feedback for instructors that do not implement CL and prepare training opportunities for instructors in order to offer awareness about CL were highly affecting the implementation of $\mathrm{CL}$. In line with this, one of the interviewed deans reported that he rarely advice instructors to practice CL even if some instructors do not fully implement. The second interviewee also said "earlier we did not try to prepare training opportunities. But this year I am thinking to prepare training opportunity by communicating instructor training university located in our surrounding". 
Table 5. College leaders related challenges/factors affecting the in implementation of CL

\begin{tabular}{|c|l|c|c|c|}
\hline No. & \multicolumn{1}{|c|}{ Items } & Response & Mean & SD \\
\hline \multirow{2}{*}{1} & College leaders inability to follow up the implementation status of CL & Instructors & 2.64 & 0.72 \\
\cline { 3 - 5 } & & Students & 2.50 & 1.00 \\
\hline \multirow{2}{*}{2} & \multirow{2}{*}{ Failure of school leaders to identify teachers that do not implement CL } & Instructors & 3.21 & 0.87 \\
\cline { 3 - 5 } & & Students & 2.70 & 0.90 \\
\hline \multirow{2}{*}{3} & Inability of school leaders to provide advice/feedback for teachers that do not implement CL & Instructors & 3.53 & 0.75 \\
\cline { 3 - 5 } & & Students & 3.58 & 0.91 \\
\hline \multirow{2}{*}{4} & Absence of reinforcement by school leaders or the government in general & Instructors & 3.43 & 0.91 \\
\cline { 3 - 5 } & & Students & 2.50 & 1.00 \\
\hline \multirow{2}{*}{5} & \multirow{2}{*}{ Lack of training (workshops) for teachers that provide awareness about CL } & Instructors & 4.07 & 0.71 \\
\cline { 3 - 5 } & & Students & 2.93 & 0.88 \\
\hline
\end{tabular}

Table 6. Students' Opinion about challenges and difficulties in CL

\begin{tabular}{|c|l|c|c|}
\hline No. & \multicolumn{1}{|c|}{ Items } & Yes (\%) & No (\%) \\
\hline 1 & Some of my team members do not do their shared work & 27.7 & 72.3 \\
\hline 2 & Some of my team members do not participate in team discussion & 54.8 & 45.2 \\
\hline 3 & Cooperative learning leads to too much noise in class & 51.9 & 48.1 \\
\hline 4 & Some of my team members are sometimes absent & 61.9 & 38.1 \\
\hline 5 & Time for team discussions is too short & 82.5 & 12.5 \\
\hline 6 & I am still unfamiliar with the cooperative learning method & 70.6 & 29.4 \\
\hline 7 & The number of students in my group is not appropriate because it is a lot & 39.1 & 61.9 \\
\hline 8 & Some of my team members dominate the group discussion & 56.1 & 43.9 \\
\hline
\end{tabular}

The above results show that the percentage of student respondents $(72.3 \%)$ who indicated that some of their team members did not do their shared work. Additionally, 54.8\% student respondents agreed that some of their team members did not participate in team discussion and most of students interviewed said that this could be solved through "encouraging and motivating us by all means of incentives, such as marks". they also seems to believe that the instructor should "check students who make noise or do not participate because, when we feel that the instructor watches, we will work hard and participate to prove our abilities". Furthermore, one of student respondent commented that "perhaps, some students are not accustomed to cooperative learning and are still attached to the traditional method".

Table 4 above shows that the percentage of students who felt that CL leads to too much noise in class varies from $51.9 \%$ to $48.1 \%$. In addition, the percentage of students who pointed out that some of their team members were sometime absent is higher $(61.9 \%)$. One of student respondent explained why this is a problem when he said, "When the group includes an excellent student and weak students, and the excellent student is absent, this affects the group's work'. In addition, the questionnaire results show that about one fourth $82.5 \%$ of the students in considered that time for team discussion was too short. One of student respondent mentioned that "the teacher gives us a few minutes to do the task but we need more time to help each other understand the task questions, so the time is not enough".

Moreover, the percentage of students who indicated that they were still unfamiliar with the cooperative learning method is higher (70.6\%). One of student respondent said, "In the secondary schools, I was used to the traditional method. Now, I have been taught by cooperative learning in some subjects for nearly one semester. I am still getting used to it". There were a small percentage of students $(39.1 \%)$ who mentioned that the group composition was not appropriate because there were too many students in the group (Table 4 above). Finally, $56.1 \%$ of the students indicated that some of their team members dominated the group discussion. One of student respondent said, "Sometimes, I get students in the group who want to dominate the discussion and do not give other members a chance to talk. However, sometime, I get students in the group who do not do that and cooperatively work. So, it depends on the group".

\subsubsection{Opinion of Supporting Factors Affecting CL}

These are the support received by the college administration and colleagues, students' perception in using CL, lesson planning and preparation, and incentives given to instructors. First of all, six instructors mentioned the direct support they received from the college administration to use CL. For instance, one of instructor mentioned "the support and encouragement instructors 
receive from college administration." One of instructors highlighted indirect support from the department head when he said, "the department head's support to use CL gives me motivation to keep using it". Another helpful source of support came from the instructors' colleagues. All participants mentioned that discussion and sharing views with each other regarding $\mathrm{CL}$ was helpful. One of instructor argued that, "an environment where issues related to cooperative learning can be discussed encourages me to carry on using this method and support other instructors who do not use it." In addition, three instructors argued that closely working with "some colleagues who teach the same course I teach to plan for the next class together" was useful.

A second important positive factor was the instructors' visits to other instructors using CL, which were considered very helpful, especially at the beginning. I5 mentioned that this "can play an important role in changing the instructor's negative perceptions and strengthening his wish for the change". Similarly, one of instructor said, "external classroom peer visits were effective for mastering that method [CL]". The follow up and visits to instructors' lessons by the training instructor was another support factor that was indicated by seven instructors. One of instructor commented that the regular follow-up for over a year helped "detect any problems arising encountered by trainee instructors and to suggest the best solutions to overcome them". Similarly, one said that, "at times when our motivation to change from traditional method to new one decreased and we were tempted to return to using the traditional lecturing method, the training instructor's visits and support renewed our enthusiasm to use CL."

\subsubsection{Conduciveness of University's Environment for the Implementation of Cooperative Learning}

Attempts were made to check the respondents' responses to implement cooperative learning. Respondents required responding the items by saying "strongly agree", "agree", "undecided", "disagree" or "strongly disagree". Responses are scored in such a way that correct response means highly conducive for the implementation of cooperative learning and incorrect response means low or not conducive for the implementation of cooperative learning. Notice that, correct responses are given to score of 5 followed by score of 4 to strongly agree and agree for respectively and incorrect responses are given to score of 1 , followed by score of 2 to responses of strongly disagree and disagree respectively.

The result presented in Table 7, indicates that the mean rating is less than 3.0 almost all the items and accordingly the average mean rating is 2.58 . This suggests that the respondents' response on classroom situation to implement $\mathrm{CL}$ is between the rating point 'disagree' and 'undecided' i.e. score of responses of 2 and 3 respectively. This tells us, the classroom situation to implement $\mathrm{CL}$ was not convenient and it affects the implementation of $\mathrm{CL}$ negatively (Table7). In addition to the above quantitative results on university environment, from instructors' and students' gathered information through interview and presents below. Interview was conducted with the instructors and students on the item, deals about problems that face him/her while he/she tries to implement CL. One of instructor replied the following: In terms of materials chairs are not easily movable to perform group work in the classroom. Reference books by itself didn't promote CL. It was found as a problem facing students while learning. Thus, we can conclude that reference books, chairs and tables are not inspiring to implement CL. Finally, the instructor was asked a question on item about other problems that she faced in the implementation of CL. She reflected that, "lack of support from college administrative, large class size and students lack of interest to participate in group work are some of the problems." Here we can understand that the above mentioned points by the instructors were factors that affect the practice of CL.

Table 7. Classroom situation for the implementation of cooperative learning

\begin{tabular}{|c|l|c|c|}
\hline No. & \multicolumn{1}{|c|}{ Items for classroom situation } & Mean & SD \\
\hline 1 & There is unavailability of instructional materials to practice CL & 2.54 & 0.82 \\
\hline 2 & Arrangement of chairs and tables are suitable to work different group activities & 2.50 & 1.00 \\
\hline 3 & The classroom situation is suitable to allow us to move around during some activities & 2.61 & 0.87 \\
\hline 4 & Reference books has adequate activities and exercises that promote cooperative learning & 2.70 & 0.90 \\
\hline 5 & There is shortage of time to practice cooperative learning in classroom & 2.53 & 0.85 \\
\hline 6 & There is enough space for interaction in groups & 2.58 & 0.91 \\
\hline & Average mean & 2.58 & 0.89 \\
\hline
\end{tabular}

Table 8. Observation results on classroom condition to implement cooperative learning

\begin{tabular}{|c|c|c|c|}
\hline No. & Classroom situations to implement cooperative learning & Yes $(\%)$ & No $(\%)$ \\
\hline 1 & The desks and chairs are easily movable & 36 & 64 \\
\hline 2 & There is enough space for interaction in groups & 24 & 78 \\
\hline 3 & The classroom is well cleaned and attractive & 62 & 38 \\
\hline 4 & There is large number of students in a class & 81 & 19 \\
\hline
\end{tabular}


As data summarized in Table 8, the classroom condition to implement CL is not good. The average number of students in each class was large i.e. 47 and it is very hard to implement CL. The desks and chairs were not easily moveable $(64 \%)$, the classroom was crowded by chairs and students $(78 \%)$ and it shows that there is no enough space for interaction in groups although the classroom was well cleaned and attractive $(62 \%)$. There is large number of students in a class $(81 \%)$. Here we can conclude that the class size was the core challenges to implement CL. In addition to the observation result about the university environment the college dean was asked the following questions and he answered as follows: The first question raised to the dean was whether the college deans encourage the use of CL method or not and if the answer is yes, how? The college dean replied:

To some extent we encourage the use of CL method by giving training for vice deans and department heads of colleges when governmental and non-governmental organizations invited the instructors to participate training. But specifically the university didn't give training for instructors on CL. In addition, the college dean add that, the instructors may face lack of understanding about CL, they may be simply understand it is like group work and classroom situation by itself is not appropriate to implement such kind of methods.

The second question raised was what mechanisms are used to motivate instructors to use CL method? He replied that "simply by creating awareness for them". The third question focused on, whether the university organizes workshop and seminars on CL for the instructors or not, as the dean replied that "the university didn't prepare it". The last question the researcher raised to the dean was, regarding possible strategies he would propose to develop more positive attitude towards $C L$. He replied:

By giving training for instructors and follow them whether they implement it properly or not is one strategy. Creating awareness for students about the importance of this method is another strategy. Finally, by doing an action research to identify the gaps in the side of instructors or students and prepare training on the gaps are some possible strategies that the university will be used to motivate instructors and students.

Based on the result of the respondents the university environment was not conducive to implement cooperative learning. To support this idea the total mean value was 2.48 that are below the average rating mean and it indicates that the school environment was not conducive. In addition to this the school principal interview result and the classroom observation found challenges like chairs were not easily movable, teacher uses only text book, large number of students in the class was some major factors that affect the implementation of cooperative learning negatively. According to Lue as cited in [21], teacher who taught many students in overcrowded classroom often say it is certainly not suitable to provide activities and group works to the class.

The college administrators' positive view of an innovation accomplished by practical support actions is a crucial factor in encouraging his/her staff to experiment with new ideas [2]. The college deans' support of the innovation can be realized in through protection from intrusion recognition of success, allocation of resources including time to participate [13]. In contrast to these ideas, in this study the college deans didn't give enough support to the instructors to implement CL. As a result, in this study, lack of support from the college deans found as a major problem for lack of practicing CL in the colleges. The instructor raised the issue in his interview that in students' reference books didn't promote implementation of CL. According to [21], the preparation of curricular materials should be based on developing problem that the curricular materials should reinforce student-centered instruction and problem solving ability of students, but in this study student' are lessee practices CL.

\section{Summary of Findings, Conclusions and Recommendations}

\subsection{Summary}

Active learning in general and CL in particular can make learning effective and interesting if it is applied in a systematic approach and well planned manner. CL is a method to the aim of student-centered classroom activities towards the attainment of the outcomes-based environment as required by accrediting and certifying bodies and agencies of higher education. Meaning, CL by itself does not bring improvements in learning unless it is implemented properly. What makes it fruitful is the way we practiced and overcome its challenges.

The study indicated that most of the instructor and student respondents have positive and good perception towards cooperative learning. However, in the actual classroom observation and interview they failed to practices CL activities and rather they tend to practices teacher-centred teaching-learning. To assure this idea students' roles like positive interdependence, doing cooperatively, taking responsibility, were unobserved activities. Similarly, instructors were not effective because some major roles like facilitating and controlling, making heterogeneous grouping, summarizing the lesson were not observed in the classes. Therefore, the instructors were not effective since they couldn't identify their major roles properly. Students' also lack interest and use passive style of learning, this hindering the practice of CL in classroom.

In relation to challenges that hinder the implementation of CL, instructors' lack of opportunities to get CL training and them preference to traditional method of teaching was found to be one of the major problems. Even if the 
instructors have got the training on active learning, there was a problem still in implementing cooperative learning. It shows that the training was not directly related to CL. This shows that the instructors don't have the detailed theoretical concept in implementing CL while they perceived cooperative learning method positively. Among others, lack of enough support from college administration (deans and department heads) and lack of effective and efficient instructional materials make the implementation of CL very difficult. Additionally, the material which could be used in class was only a lecture note used dominantly. The students' interview and classroom observation assured this through their response. The other point considered in this study was the classroom condition. Chairs and tables in classrooms were not easily moveable and there were large number of students in class.

\subsection{Conclusions}

Over the last three decades, CL method has been widely researched and a number of studies have indicated the effectiveness of using this method to improve learners' social and academic performance when working in small cooperative groups. The literature review on $\mathrm{CL}$ shows that most empirical studies in the field focus on assessment with only a few studies in the area of practices, perceptions and challenges this is the case in Ethiopian higher educations. The improvement of instructors and students' understanding of $\mathrm{CL}$ and its implementation is, however, unlikely to be achieved if researcher is only concerned with achievement.

Implementing CL in university help instructors' and students' classes has played an essential role in changing these classes from teacher-centred learning to student-centred learning. Instructors delegated some authority and responsibility for learning to students in the class instead of delivering information to students and instructor. However, there are some initial challenges that instructors face when they change from teacher-centred to student-centred learning and there are also factors that can help instructors overcome these challenges and support them to use CL in their classes. The result shows that instructors seemed to understand and implement the CL method to a quite effective degree in most cases. Although there were individual differences among the instructor participants regarding the way to implement $\mathrm{CL}$, most of them have shown the ability to do that quite effectively. There are three main factors that affect instructors' implementation of the CL and the ways they promote them: instructors' knowledge and understanding of the principles of CL, students' familiarity and experience with CL, and limited lesson time.

As the study indicated, for the major challenges that block the implementation of CL all (i.e. instructors, students and administrative bodies) were accountable. The instructors are part of the problem because of lack of knowledge about CL, and lack of positive attitude towards CL. Students on their part preferred traditional style of learning and lack of motivation to participate in CL. Moreover, lack of administrative support, unavailability of instructional materials exaggerates problems. From this, we can conclude that the university environment was not suitable for the implementation of CL. As indicated in the findings, the material that was used in the classroom was only a lecture note. Materials like charts and information gap activities etc. were not accustomed. To conclude this, unavailability of instructional materials were part of lack of implementing CL.

The study pointed out that the guiding principles of CL have been ignored practically. In current $C L$ and teaching process instructor's role were facilitator, monitor, assist with needs etc. but we couldn't see this in reality. Not only this but also the core point that make up CL like students active participant, develop their social skills, and all group members should be contribute their contribution for group were not reflected in the teaching-learning process. Thus, it is possible to conclude that both instructors and students couldn't identify their roles because of lack of awareness on the guiding principle of CL.

\subsection{Recommendation}

Based on the findings of the study, the researcher would like to forward the following recommendations for the improvement of the practices of cooperative learning.

1. An appropriate support should be provided by concerned bodies (i.e deans, department heads, administrative, ministry of education) need to train instructors and students to create awareness on the concept of CL and how to convert those concepts into practical. The instructors should develop an efficient and effective mechanisms to assess students' cooperation rather competition and following up its progress. Instructors also give marks on the basis of the individual learning of all group members; that is, the average scores on quizzes which the student shares without teammates help. In order for the team to succeed, all the team members must have learned so that one or two students do not do all the work.

2. Arsi University should provide resources needed for the effective implementation of CL approach. Further the University should organize seminars and workshops for instructors on the application of cooperative learning methods for effective skill acquisitioning.

3. The deans and department heads in collaboration with Ministry of Education should co-ordinate to invite experts in the field to share his/her experience of using $\mathrm{CL}$ and to suggest an alternative techniques in the absence of adequate teaching aids and supplementary materials. 
4. As can be observed, always the instructors were solely depending on students' lecture note. This can often create a danger on expanding the knowledge of their students since other instructional materials were neglected. Hence, instructors should give due attention for other instructional materials while he/she implement CL in their classes. This can make their students to be flexible and knowledgeable on different issues.

5. Class size was found as one of the challenge for implementing CL. The number of students should be appropriate class. Therefore, proper attention should be given while assigning students to different classes.

6. Further, investigations should be carried out on this issue which will consist of large number of samples of instructors at different universities; hence, it could help to re-assure the reliability and validity of this research paper.

\section{REFERENCES}

[1] Ahmed, Z., \& Mahmood, N. (2010). Effects of Cooperative Learning vs. Traditional Instruction on Prospective Teachers' Learning Experience and Achievement. Journal of Faculty of Educational Sciences, 43(1), 11-164. Retrieved from http://dergiler.ankara.edu.tr/dergiler/40/1342/15555.pdf

[2] Altun, S. (2015). The Effect of Cooperative Learning on students' achievement and vis on the science and technology curse. International Electronic Journal of Elementary Education, 7(3), 451-468.

[3] Almulla, M. (2016 a) Students' perceptions of the academic and social Benefits of working with cooperative learning, Global Journal of Business and Social Science Review, 4 (4), pp.8-21.

[4] Almulla, M. (2016 b) An investigation of Saudi teachers' perceptions towards training in cooperative learning, PEOPLE: International Journal of Social Sciences, 2 (1), pp. 715-737.

[5] Amedu, O \& Gudi, K (2017). Attitude of Students towards Cooperative Learning In Selected Secondary Schools in Nasaraw State. Journal of Education and Practice, 8 (1), 29-34.

[6] Aragaw, D .(2015). The Effect of Cooperative Learning On Students EFL Reading Comprehension: Meshentie Grade 9 High School Students. Educational Journal, 4(5), 222-231, (dio-10.11648/j.edu.20150405.16)

[7] Aschalew, T.(2013). Teachers Perception and Practice of Active Learning in Haramaya University. An International Multidisciplinary Journal. 1(6). pp. 370-390.

[8] Aziz, Z. \& Hossain, M. A. (2010). A comparison of cooperative learning and conventional teaching on students' achievement in secondary mathematics. Procedia Social and Behavioral Sciences, 9, 53-62.

[9] Baloche, L. (2011). A brief view of cooperative learning from across the pond, around the world, and over time. Journal of Co-operative Studies, 44(3), 25-30

[10] Batool, S., \& Perveen, Q. (2012). Effect of cooperative learning on achievement of students in general science at secondary level. International Education Studies, 5(2). doi:10.5539/ies.v5n2p154

[11] Belilew, M. (2015). Practices and Challenges of Implementing Cooperative Learning: Ethiopian High Schools EFL Teachers Perspective. International Journal of Current Research, 7(12), 24584-24593.

[12] Birhanu, M. (2010).Active Learning Approaches in Mathematics Education at Universities In Oromia, Ethiopia. (Doctoral Dissertation). University of South Africa.

[13] Bilen, D \& Tavil, Z (2015). The Effect of Cooperative Learning Strategy on Vocabulary Skills of 4th Grade Students. Journal of Education and Training Studies, 3(6), 151-165.

[14] Cohen, L., Manion, L. and Morrison, K.(2011).Research methods in education.7th edn. London: Routledge.

[15] Connolly, P. (2007). Quantitative data analysis in education: A critical introduction using SPSS. 1st edn. London: Routledge.

[16] Dejene Mendera. (2011). An Investigation of the Role of Cooperative Learning Enhancing Students' Writing Performance in Shambu Preparatory School Grade 11 Students in Focus. (MA Thesis). Addis Ababa University, Addis Ababa.

[17] Dheeraj, D., Kumari, R. (2013). Effect of cooperative learning on Achievement in environmental science of school student. International Journal of Scientific and research publications,3(2). Retrieved May 6, 2014 from www.ijsrp.org.

[18] Farzaneh, N \& Nejadansari, D. ( 2014). Students' Attitude towards Using Cooperative Learning for Teaching Reading Comprehension. Journal of Theory and practice in language studies Vol. 4, No. 2, pp. 287-292.

[19] Garcha, P. S. \& Kumar, K. (2015). Effectiveness of cooperative learning on critical thinking disposition of secondary school students. Issues and Ideas in Education, 41-62.

[20] Gillies R. M.,\& Boyle, M. (2011). Teachers' reflections on cooperative learning (CL): a two-year follow-up. Teach. Educ, 1 63-78.

[21] Hagos, H. (2012). The Major Challenges of Implementing Active Learning in EFL Classes of Wolita Sodo University. (MA Thesis). Addis Ababa University, Addis Ababa.

[22] Inuwa, U. , Abdullah, Z. \& Hassan, H. (2015). Effects of cooperative learning on secondary students' achievement in financial accounting. (ICAS), International Conference on Accounting Studies.

[23] Javed, A, .Saif, N. \& Kundi, G. M. (2013). The study of effectiveness of cooperative learning approach in teaching of mathematics at secondary levels in Pakistan. Mathematical Theory and Modeling, 3(10

[24] Johnson, D. W., \& Johnson, R. T. (2010). An educational psychology success story: Social interdependence theory 
and cooperative learning. Educational Researcher, 365-379.

[25] Johnson, D. W., Johnson, R. T., \& Tjosvold, D. (2012). Effective cooperation, the foundation of sustainable peace. Psychological components of sustainable peace. New York: Springer

[26] Jolliffe, W. (2015). Bridging the gap: teachers cooperating together to implement cooperative learning. Education 3-13: International Journal of Primary, Elementary and Early Years Education(1), 70-82

[27] Kuri, S. (2013). Effect of cooperative learning model on the IX standard students' achievement towards geography with respect to gender. International Indexed and Referred research Journals, IV(43-44).

[28] Kyndt, et al. (2013). A meta-analysis of the effects of face-to-face cooperative learning. Do recent studies falsify or verify earlier findings? Educational Research Review, 133-149.

[29] Lau, P., Kwong, T., Chong, K. \& Wong, E. (2014). Developing students' teamwork skills in a cooperative learning project. International Journal for Lesson and Learning Studies, 3(1), 80-99.

[30] Lirola, M. M. (2016). A proposal to combine cooperative learning and peace education in a foreign language subject. Journal of Global Research in Emaria Martinez Lirolamaría Martínez Lirol Aducation and Social Sciences, 5(2), 102-111.

[31] Mashhadi, H., \& Gazorkhani, A. M. (2015). Effectiveness of cooperative learning (participation)method in academic achievement of students in teacher training centers. Journal of Social Issues \& Humanities, 3(5).

[32] Mehta, S \& Kulshrestha, A (2014). Implementation of Cooperative Learning in Science: A Developmental-Cum Experimental Study. Journal of Educational Research International. Dio: 10.1155/2014431542

[33] Muhammed, K .(2014). Cooperative Learning Practices in College of Education and Behavioral Sciences in Haramaya University. International Journal of Science and Research, 3(11): 3044-3051.

[34] Najmonnisa. (2013). A readiness study about cooperative teaching learning practices at schools level in Karachi: Issues and challenges. UnPublished PhD Dissertation.

[35] Ning, H. \& Hornby, G. .(2014). The impact of cooperative learning on tertiary EFL learners' motivation. Educational Review, 66(1), 108-124. doi:10.1080/ 0013 1911.2013.853169

[36] Phiwpong, N. \& Dennis, N. K. (2016). Using cooperative learning activities to enhance fifth grade students` reading comprehension skills. International Journal of Research Granthaalayah, 4(1), 146-152.

[37] Ramos, M. C., \& Pavón, V. (2015). Developing cooperative learning through tasks in Content and Language Integrated Learning. Multidisciplinary Journal of Educational Research, 5(2), 136-166. doi:10.17583/remie.2015.1429

[38] Sharan, Y. (2015). Meaningful learning in the cooperative classroom. Education 3-13: International Journal of Primary, Elementary and Early Years Education, 43(1), 83-94. doi:10.1080/03004279.2015.961723
[39] Slavin, R. (2014) Educational psychology: Theory and practice. 10th edn. Harlow: Pearson Educational Limited.

[40] Slavin, R. E. (2015). Cooperative learning in elementary schools. Education. International Journal of Primary, Elementary and Early Years Education, 43(1), 3-13.

[41] Song, Y. (2012). Application of cooperative learning in the college task-based teaching. Journal of Exam Week, 27, 83-84.

[42] Teweldebrhan Abrha (2015). Attitude of Students towards Cooperative Learning the Case of Wolaita Sodo University Psychology Department Students. International Journal of Sciences, 24(2), 33-44.

[43] Thanh, P,T. (2011). An Investigation of Perception of Vietnams Teachers and Students towards Cooperative Learning. International Educational Studies, 4(1), 3-12.

[44] Tsay, M \& Brady, M (2010). A Case Study of Cooperative Learning and Communication Pedagogy. Journal of Scholarship of Teaching and Learning, 10(2), 78-89.

[45] Weldemariam, N \& Girmay, T (2015). The Practices of Student Network as Cooperative Learning in Ethiopia. African Education Review, 12(4): 696-712, DIO: $10.1080 / 18146627.2015 .1112162$

[46] Wondwosen, T. (2017). Students Attitude towards Cooperative Learning in EFL Writing Class. Educational Journal, 2(3). 60-68

[47] Wolfensberger, B. \& Canella, C. (2015). Cooperative Learning about nature of Science with a case from the history of Science. International Journal of Environmental \& Science Education, 10(6), 865-889.

[48] Wossen, M. (2011). Assessing Students' and Teachers' Perception and Classroom Practice of Cooperative Learning in EFL Classes.(MA Thesis). Addis Ababa University, Addis Ababa. 